\title{
MICRO-METHOD FOR THE ESTIMATION OF THE SEDIMENTATION RATE OF RED CELLS
}

\author{
BY \\ HILDA TROUGHT, B.Sc. \\ (Biochemist, Dudley Road Hospital, Birmingham)
}

Although there are already many macro-methods in vogue for the estimation of the sedimentation rate of the red cells of the blood, the finger-prick methods so far reported do not appear to receive widespread application owing to a certain lack of confidence in the reliability and accuracy of the results obtained thereby.

The micro-method described below has at least one obvious advantage in that the 0.3 c.c. of blood used, reasonably easily obtained by capillary puncture, is accurately measured in a graduated pipette, instead of counting drops of blood the size of which may vary with their pathological consistency.

The method was tried in cases of rheumatism, rheumatic carditis, chorea, and allied conditions in childhood, thus obviating for these young patients a series of venupunctures by which to check and control the improvement or otherwise of their clinical condition.

\section{Apparatus required}

1. Special capillary blood pipettes graduated at 0.04 and $0 \cdot 1$ c.c.

2. Special micro-sedimentation tubes graduated in $50 \mathrm{~mm}$. divisions, the cubic capacity of the graduated portion being less than $0 \cdot 25$ c.c. and the height of the tube being $70 \mathrm{~mm}$.

3. Ordinary small test tubes for receiving blood and mixing with citrate.

4. Ordinary capillary tubes with a rubber teat attached.

5. 5 per cent. sodium citrate solution.

\section{Method}

The sodium citrate solution is drawn up into the blood pipette three times, and the last time 0.04 c.c. is delivered into one of the small test tubes. Blood is then drawn up into the pipette to the $0 \cdot 1$ c.c. mark three times, and each time is expelled into the small tube containing the 0.04 c.c. citrate, and is very thoroughly mixed to prevent formation of clots.

The mixture is then carefully drawn up into a capillary tube and is expelled into the micro-sedimentation tube without the formation of bubbles. The sedimentation tube is then placed vertically and readings are taken at half an hour and one hour exactly. 
Sixteen normal cases were investigated and from the results the normal reading for the half-hour varied from 0 to $5 \mathrm{~mm}$., and for the one hour, readings varied from 1 to $10 \mathrm{~mm}$.

NORMAL CASES

\begin{tabular}{|c|c|c|c|c|c|c|c|}
\hline \multicolumn{2}{|c|}{ PATIENT } & \multirow[b]{2}{*}{$\begin{array}{c}\text { HALF-HOLR } \\
\text { mm. } \\
1.0 \\
2.0 \\
2.0 \\
3.0 \\
3.0 \\
1.0 \\
2.0 \\
2.0\end{array}$} & \multirow[b]{2}{*}{$\begin{array}{c}\text { ONE HOUR } \\
\text { mm. } \\
2.0 \\
8.0 \\
6.0 \\
9.0 \\
7.0 \\
8.0 \\
3.0 \\
6.0\end{array}$} & \multicolumn{2}{|c|}{ PATIENT } & \multirow[b]{2}{*}{$\begin{array}{c}\text { HALF-HOUR } \\
\text { mm. } \\
5.0 \\
0.0 \\
1.0 \\
2.0 \\
5.0 \\
1.0 \\
2.0 \\
3.0\end{array}$} & \multirow[b]{2}{*}{$\begin{array}{c}\text { ONE HOUR } \\
\mathrm{mm} . \\
8 \cdot 0 \\
1.0 \\
1.5 \\
4.5 \\
7.5 \\
2.0 \\
4.0 \\
5.0\end{array}$} \\
\hline $\begin{array}{l}1 . \\
2 . \\
3 . \\
4 . \\
5 . \\
6 . \\
7 . \\
8 .\end{array}$ & $\begin{array}{l}\text { O. T. } \\
\text { R. G. } \\
\text { D. R. } \\
\text { D. G. } \\
\text { M. R. } \\
\text { D. H. } \\
\text { D. D. } \\
\text { D. B. }\end{array}$ & & & $\begin{array}{l}9 . \\
10 . \\
11 . \\
12 . \\
13 . \\
14 . \\
15 . \\
16 .\end{array}$ & $\begin{array}{l}\text { F. L. } \\
\text { F. F. } \\
\text { V. S. } \\
\text { V. H. } \\
\text { E. D. } \\
\text { R. T. } \\
\text { D. B. } \\
\text { B. C. }\end{array}$ & & \\
\hline
\end{tabular}

Thirty-four cases of acute rheumatism, rheumatic carditis, erythema nodosum, chorea and arthritis, were tested and gave the following results:

\begin{tabular}{|c|c|c|c|c|c|c|c|c|}
\hline & & & \multicolumn{2}{|c|}{ IST WEEK } & \multicolumn{2}{|c|}{ 2ND WEEK } & \multicolumn{2}{|c|}{ 3RD WEEK } \\
\hline & & & $\frac{1}{2}$ HOUR & 1 HOUR & $\frac{1}{2}$ HOL'R & 1 HOLR & $\frac{1}{2}$ HOLR & 1 HOUR \\
\hline $\begin{array}{l}\text { E. W. } \\
\text { E. T. } \\
\text { D. M. } \\
\text { I. H. } \\
\text { D. I. } \\
\text { E. T. } \\
\text { E. W. } \\
\text { B. B. } \\
\text { A. G. } \\
\text { I. G. } \\
\text { E. N. } \\
\text { O. T. } \\
\text { F. L. } \\
\text { L. M. } \\
\text { D. N. } \\
\text { E. F. } \\
\text { D. R. } \\
\text { E. N. } \\
\text { D. T. } \\
\text { E. F. } \\
\text { D. S. } \\
\text { E. S. } \\
\text { V. H. } \\
\text { R. C. } \\
\text { B. Y. } \\
\text { D. D. } \\
\text { J. C. } \\
\text { E. B. } \\
\text { D. E. } \\
\text { D. T. } \\
\text { D. B. } \\
\text { I. P. } \\
\text { E. F. } \\
\text { I. H. }\end{array}$ & 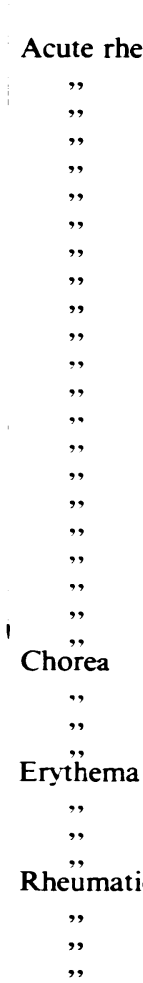 & 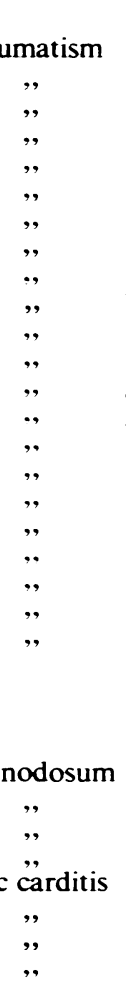 & $\begin{array}{r}\mathrm{mm} . \\
25.0 \\
22.0 \\
11.0 \\
16.0 \\
11.0 \\
17.0 \\
9.0 \\
15.0 \\
26.0 \\
8.0 \\
13.0 \\
12.0 \\
8.0 \\
5.0 \\
8.0 \\
9.0 \\
20.0 \\
6.0 \\
23.0 \\
23.0 \\
28.0 \\
12.0 \\
11.0 \\
11.0 \\
18.0 \\
4.0 \\
10.0 \\
19.0 \\
15.0 \\
15.0 \\
8.0 \\
5.0 \\
12.0 \\
8.0\end{array}$ & $\begin{array}{c}\mathrm{mm} . \\
30.0 \\
26.0 \\
18.0 \\
22.0 \\
28.0 \\
23.0 \\
16.0 \\
20.0 \\
28.0 \\
14.0 \\
23.0 \\
18.0 \\
14.0 \\
11.0 \\
15.0 \\
15.0 \\
28.0 \\
10.0 \\
28.0 \\
28.0 \\
30.0 \\
24.0 \\
18.0 \\
15.0 \\
23.0 \\
10.0 \\
15.0 \\
24.0 \\
18.0 \\
21.0 \\
15.0 \\
13.0 \\
26.0 \\
12.0\end{array}$ & $\begin{array}{r}25.0 \\
6.0 \\
5.0\end{array}$ & $\begin{array}{r}29 \cdot 0 \\
12.0 \\
8.0\end{array}$ & $\begin{array}{l}5 \cdot 0 \\
3 \cdot 0\end{array}$ & $\begin{array}{l}11.0 \\
10.0\end{array}$ \\
\hline
\end{tabular}


In ten of these cases the sedimentation rates were repeated at weekly intervals, and the results obtained agreed with the clinical course of the disease.

A further series of tests were carried out on placental bloods, in order to see whether the pregnancy high sedimentation rates were reproduced in the blood of the newly-born. In eight specimens of placental blood and in two specimens of blood from normal babies only a few days old, no increases in the sedimentation rate were observed.

It has been shown that:

\section{Summary}

(a) Normal readings are 0 to $5 \mathrm{~mm}$. for half an hour, and 0 to $10 \mathrm{~mm}$. for one hour.

(b) Moderately acute cases give readings of $8 \mathrm{~mm}$. for half an hour and $14 \mathrm{~mm}$. for one hour.

(c) Gravely acute cases give readings of $20 \mathrm{~mm}$. for half an hour and $30 \mathrm{~mm}$. for one hour.

Thanks are due to Dr. W. Gaisford, F.R.C.P., late of this hospital, for his permission to carry out these tests on selected cases from his childrens' wards, and to the nursing staff of these wards for their assistance and co-operation in obtaining the necessary specimens. Thanks are also due to $\mathrm{Mr}$. Wentworth Taylor, F.R.C.S., for permission to obtain specimens from the maternity wards. 